\title{
Autonomia para ensinar e aprender: pela liberdade na prática pedagógica
}

\author{
Geraldo Mateus de Sá* - PUC-GOIÁS \\ Aldimar Jacinto Duarte* - PUC-GOIÁS
}

\section{Resumo}

Este artigo pretende refletir sobre ensinar e aprender a partir do conceito de autonomia, de Paulo Freire (1921-1997), que pressupõe a pedagogia pautada na liberdade, na democracia e no diálogo. Assim, salienta-se a necessidade da livre manifestação da curiosidade, a fim de que a prática pedagógica autoritária não iniba a invenção e, muito menos, negue a dimensão crítica da aprendizagem existencialmente manifestada no mundo. Em vista disso, fez-se uma análise do conceito de autonomia concernente ao pensamento de Freire, especialmente no que tange à sua obra Pedagogia da autonomia (1996). Dentre os possíveis resultados, conclui-se que a autonomia, além de necessária à práxis pedagógica, constitui também uma real alternativa de uma pedagogia inventiva e autêntica dentro da realidade

* Graduação em Filosofia pela UNIFAI - Centro Universitário Assunção/SP, mestrado em Educação pela UFSJ, professor do Departamento de Filosofia e Ciências Sociais (DFCS) da Universidade do Estado do Pará (UEPA/Campus VII), PA, Brasil. Doutorando em Educação pela Pontifícia Universidade Católica de Goiás - PUC Goiás. Membro do Núcleo de Estudos Corpo, Cultura, Linguagem e Expressão (NECCEL) da UFSJ e do Grupo de Estudos e Pesquisa Social - GEPES, da Universidade do Estado do Pará. Pesquisas em Filosofia da Educação e Paulo Freire. E-mail: geraldo.sa@uepa.br

** Graduação em História pela Pontifícia Universidade Católica de Goiás , mestrado em Educação Brasileira pela Universidade Federal de Goiás e doutorado em Educação pela Universidade Federal de Goiás . Atualmente é professor adjunto da Pontifícia Universidade Católica de Goiás. É Professor do Programa de Pós Graduação em Educação - Mestrado e Doutorado - da PUC Goiás e, pesquisador nas áreas de juventude e, história e memória em: EJA, Educação Popular e Movimentos Sociais. Encontra-se como Coordenador do Programa de Pós Graduação em Educação (PPGE) da PUC Goiás e Vice Coordenador do FORPRED Centro Oeste. E-mail: aldimarjd@hotmail.com 
educacional. A análise em questão evidencia, portanto, que a identidade do pensamento de Freire consiste prioritariamente em uma concepção crítica à autonomia para ensinar e aprender.

Palavras-chave: Autonomia. Paulo Freire. Liberdade. Invenção. Curiosidade.

\section{Autonomy to learn and teach: for the freedom in the pedagogical action}

\section{Abstract}

This article aims to reflect on teaching and learning from the concept of autonomy, by Paulo Freire (1921-1997), which implies pedagogy based on freedom, democracy and dialogue. Accordingly, it is important to highlight the free expression of curiosity so that the authoritarian pedagogical practice does not inhibit the invention and, much less, denies the critical dimension of learning existentially manifested in the world. In view of this, an analysis was made of the concept of autonomy concerning Freire's thought, especially with regard to his work Pedagogia do autonomia (Pedagogy of autonomy, 1996). Among the possible results, it is concluded that autonomy, in addition to being necessary for pedagogical praxis, is also a real alternative to an inventive and authentic pedagogy within the educational reality. The analysis shows, therefore, that the identity of Freire's thought consists primarily of a critical conception of autonomy to teach and learn.

Keywords: Autonomy. Paulo Freire. Freedom. Invention. Curiosity.

\section{Autonomía para enseñar y aprender: por la liber- tad en la práctica pedagógica}

\section{Resumen}

Este artículo tiene como objetivo reflexionar sobre la enseñanza y el aprendizaje a partir del concepto de autonomía de Paulo Freire (1921-1997). Se asumió que este es un concepto crucial en la perspectiva pedagógica de este educador. Así, su pensamiento, fundado en la concreción del mundo, denota una práctica pedagógica autónoma y sólidamente fundamentada en la relación entre los hombres entre ellos y con el mundo. La autonomía, en el sentido freiriano, presupone una pedagogía basada en la libertad, la democracia y el diálogo. Así, se enfatiza la necesidad de la libre expresión de la curiosidad, para que la práctica pedagógica autoritaria no inhiba la 
expectativa de la invención y, mucho menos, niegue la dimensión crítica del aprendizaje existencialmente manifestada en el mundo.

Palabras clave: Autonomía. Paulo Freire. Libertad. Invención. Curiosidad.

\section{Introdução}

Paulo Freire nasceu no Nordeste brasileiro, Recife, em 1921. E faleceu em São Paulo, em 1997. Após mais de duas décadas de sua morte, ainda figura entre os mais influentes educadores contemporâneos, no Brasil e no mundo. Foi um educador inovador da prática pedagógica, principalmente por utilizar uma linguagem crítica, humanizadora e conceitualmente inventiva, de tal maneira, carregada de sonhos e de utopia para se poder transformar o homem e o mundo. Protagonizou um pensamento voltado, especialmente, para a educação e a formação da consciência crítica, tanto no contexto político quanto pedagógico, cujo principal intuito foi promover a libertação mútua do dominado e do dominador, a fim do ser mais.

Assim, o pensamento freiriano, gestado na concretude da realidade, a partir de uma vivência histórica enraizada existencial e dialeticamente na relação do homem com o mundo, continua como um apelo radical à conscientização política e à libertação do homem em sua totalidade. Dessa forma, o ideal pedagógico freiriano foi marcado pela busca da autonomia, que personifica a liberdade do corpo e do espírito sem, contudo, deixar de perceber que educar é condição intrínseca ao inacabamento da conscientização e da libertação do homem em sua totalidade.

Freire fundamentou seu discurso crítico e consciencioso sobre a teoria e a prática da pedagogia comprometida com a libertação, a formação e a plena valorização de homens e mulheres, sobretudo, em razão de se efetivar a autonomia e o ser mais. Sua ação pedagógica foi coesa em relação à conscientização política e, ao mesmo tempo, embrionária do processo de libertação do oprimido de sua condição de hospedeiro do opressor. Nessa perspectiva, abriu-se nova frente para se pensar a educação comprometida com a liberdade e a autonomia do indivíduo que, se fazendo contrário às 
circunstâncias opressivas manifestadas em sua realidade, espera tornar-se capaz de resistir e de se opor a qualquer forma de opressão.

Freire, no entanto, não foi um educador além do seu tempo, como muitos enfatizam, ele assim se fez no enfrentamento da lógica da opressão. Ao propor a pedagogia da autonomia percebeu, em seu contexto histórico, a necessidade de libertar quem ensina e quem aprende das amarras da pedagogia da dominação, historicamente, consubstanciada no autoritarismo como negação do ser mais.

Comprometido com a liberdade e a democracia, o seu ideal pedagógico foi ambientado em princípios éticos, na manifestação da competência profissional e na disposição para o diálogo entre educador e educando. Destarte, o indivíduo existencial e dialeticamente concebido por ele é aquele que, ciente de seu papel político e pedagógico, empenha-se em construir uma sociedade mais humanizada e, de modo consequente, solidária com as circunstâncias imanentes à condição de cada indivíduo em sua relação irremissível com o outro e com o mundo.

O pensamento freiriano se manifesta na preocupação com a existencialidade humana implicada nas questões políticas, pedagógicas, epistemológicas, estéticas, éticas, etc. Nessa percepção, pode-se garantir que a pedagogia da autonomia inexiste sem o comprometimento ético e a prática pedagógica reflexiva que, por sua vez, deve culminar em ação uma respeitosa pelo saber do outro. Em consequência disso, também se refuta a discriminação, o preconceito e o cerceamento da diversidade cultural ou ideológica, práticas estas não raramente reafirmadas através das convenções pedagógicas autoritárias.

Em concordância com a acepção freiriana, há que se guardar um profundo respeito aos saberes dos educandos e a sua construção social, bem como a competência profissional do educador que, então, deve ser pautada na rigorosidade científica e na humildade acadêmico-intelectual como conduta adjacente à práxis da pedagogia da autonomia. Aí, consequentemente, se concebe a noção de que, devido às próprias circunstâncias da condição humana, o 
educador também tem que se dar conta de que quem ensina precisa, em quaisquer circunstâncias, se dispor a aprender. Sendo assim, a postura de Freire consente que o educador se reconheça como alguém que, por vezes, também ignora, mas, ao mesmo tempo, sabe não possuir a onipotência do conhecimento definitivo.

As convicções freirianas relativas à autonomia, por certo, se efetivam nas bases da pedagogia da libertação, sendo esta capaz de promover a liberdade tanto dos educadores quanto dos educandos, cuja finalidade consiste, basicamente, em desarraigar quaisquer formas de autoritarismo pedagógico. Seu pensamento, que se engendrou na concretude do mundo, emergiu a pedagogia da autonomia, democrática e desconstrutiva dos arcaísmos operantes na educação autoritária.

Precisamente, pode-se dizer que Freire sempre pactuou com o ideal da liberdade existencialmente ambientada na realidade brasileira. Investiu esperança e preferência por aqueles que, ao longo da história, foram minorados por alguma forma de opressão e que, por consequência, também constituía uma maneira bem-sucedida de restringir o senso de autonomia, especialmente o da autonomia pedagógica. De modo geral, seu pensamento contestou a opressão e buscou conferir liberdade e autonomia aos oprimidos. Nessa perspectiva, pode-se dizer que o autor de Pedagogia da autonomia (1996) desejou a liberdade de se poder pensar a própria realidade e a complexa dimensão humana na sua intrínseca relação com o mundo.

Manifestadamente contrário a quaisquer formas de opressão, Freire desenhou-se como pensador propositivo do entendimento de pensar e de ensinar, considerando, para tanto, a predisposição da autonomia pedagógica em relação ao ato de educar e, porventura, de se auto-educar. Levou em consideração diferentes formas de compreender o mundo e conferir sentido à própria existência. Considerou a pluralidade cultural, as diferenças geográficas, sociais e econômicas que, histórica e dialeticamente, compõe o mosaico da realidade brasileira. 
Acreditava que é pela via da ética e da autonomia que se concretiza a ação educativa, prioritariamente, entendida como efetivação da liberdade. Valorizou a existencialidade da vida e se opôs a tudo que, de alguma forma, pudesse negar a autonomia como necessidade imprescindível da existência humana implicada nas circunstâncias do mundo.

Por conseguinte, o objetivo deste trabalho consiste, basicamente, em discutir a conceito de autonomia idealizado por Freire e as respectivas implicações de homens e mulheres envolvidos na experiência pedagógica. Em vista disso, fez-se uma análise do conceito de autonomia concernente ao pensamento de Freire, especialmente no que tange à sua obra Pedagogia da autonomia (1996). Dentre os prováveis resultados, conclui-se que a autonomia, além de necessária à práxis pedagógica, notou-se que ela constitui, também, uma real possibilidade de uma pedagogia inventiva e autêntica dentro da realidade educacional. A análise em questão evidencia, portanto, que a identidade do pensamento de Freire consiste prioritariamente em uma concepção crítica à autonomia para ensinar e aprender no âmbito de uma educação radical e libertadora.

\section{A pedagogia da autonomia: a liberdade para ensinar e aprender}

No contexto da educação brasileira, muitas vezes, educadores e educandos vivenciam limitações oriundas da cultura pedagógica autoritária. É dessa cultura que, costumeiramente, se negou "a educação e o conhecimento como processos de busca" (FREIRE, 2019 , p. 81), quer dizer, como promoção de autonomia de todos os entes envolvidos no processo pedagógico. Nessa lógica, a autonomia constitui "uma das categorias centrais na obra de Freire" (MACHADO, 2017, p. 53) ou de qualquer outro sistema educacional vocacionado à prática da liberdade. $\mathrm{Na}$ verdade, ela consiste numa "tarefa fundamental no ato de educar, ligada a outros princípios basilares da prática educativa” (MACHADO, 2017, p. 53) e, sobretudo, "do direito pessoal na construção de uma sociedade 
democrática que a todos respeita e dignifica" (MACHADO, 2017, p. 53), a fim do ser mais.

$\mathrm{Na}$ contramão da pedagogia da autonomia, os educadores, por muitas vezes, tiveram suas experiências de educar ou de serem educados/reeducados marcadas pela educação opressora. Nesse caso, pode-se notar a manifestação daquela educação especializada em transmitir conteúdos descontextualizados ou alheios às experiências vivenciadas concretamente no mundo por educandos e educadores. E, nesse significado, o espírito inventivo, quase sempre, foi ofuscado pela imposição de conteúdos pré-dados e institucionalizados de forma subserviente aos paradigmas da pedagogia autoritária.

Desse ponto de vista, a Pedagogia da autonomia (1996) se mostrou como apelo inexorável à transformação da educação, da pedagogia e, impreterivelmente, das condições existenciais e ontológicas do ser mais. Segundo Machado (2017), esta obra foi onde Freire escreveu e refletiu "sobre esse conceito, colocando-o como um princípio pedagógico para educadores que se dizem progressistas" (MACHADO, 2017, p. 53) e comprometidos com a educação humanizada e humanizadora. Assim, conforme Freire (1996), almeja-se que a transformação do mundo implique "a dialetização entre a denúncia da situação desumanizante e o anúncio de sua superação, no fundo, o (...) sonho" (FREIRE, 1996, p.79) humanamente possível de mudar o homem para que, de forma compromissada com a humanização do outro, também se compreenda a inconclusão da educação crítica e libertadora.

Diante desse modo de pensar a educação, é primordial transcender o anacronismo das práticas pedagógicas autoritárias, sobretudo em virtude de não mais se intentar a transmissão do saber impositivo, que inibe a inventividade de outras formas de ensinar e de aprender. A concepção pedagógica autoritária - imanente à educação reacionária/bancária - reiteradamente reprime a autonomia e a intuição inovadora e, na sua versão mais perversa, mata o sonho e a utopia, para, por último, aniquilar as possibilidades do ser mais, 
considerando, para tanto, a rejeição do contexto de sua existencialidade histórica.

O pensamento em questão consiste, portanto, na superação da restrição à pluralidade dos saberes e à promoção da pedagogia da autonomia, crítica e ética. O saber estagnado, que se dispõe "a petrificar-se ou a fazer algo quase morto" (FREIRE, 2019, p. 79), tradicionalmente, castra o desejo de aprender e a liberdade de ensinar. Por isso, o ato de "ensinar não pode ser um puro processo (...) de transferência de conhecimento do ensinante ao aprendiz" (FREIRE, 1997, p. 23), sobretudo, em se tratando daquela transferência mecânica que, quase tirânica, frustra a curiosidade de educadores e de educandos.

É por essa razão que não se deve operacionalizar o conhecimento mecânico, do qual resulta uma "memorização maquinal" (FREIRE, 1997, p. 23) e rasa, como o próprio Freire criticava. Assim sendo, a um "estudo crítico corresponde um ensino igualmente crítico que demanda necessariamente uma forma crítica de compreender e de realizar a leitura da palavra e a leitura do mundo" (FREIRE, 1997, p. 23), principalmente ao se levar em conta o repertório das implicações da práxis pedagógica manifestadas nos contextos histórico, político, social, etc. Esse tipo de leitura é necessário tanto a quem ensina quanto a quem se coloca na condição de educando. É por esse motivo que, conforme Oliveira (1996), faz-se indispensável a ação pedagógica "fundada na ética, no respeito à dignidade e à própria autonomia do educando" (OLIVEIRA, 1996, p. 10) entendido, também, como sujeito de sua aprendizagem.

A formalidade da "competência técnico-científica e o rigor de que o professor não deve abrir mão no desenvolvimento de seu trabalho, não são incompatíveis com a amorosidade necessária às relações educativas" (FREIRE, 1996, p. 10) no campo da estética, da ética e da intuição inventiva. Porém, a práxis pedagógica, bem como "a segurança com que a autoridade docente se move implica [também] sua competência profissional" (FREIRE, 1996, p. 91), que deve ser precedida do comprometimento ético e da sua experiência cotidiana, isto é, levando-se em consideração a autonomia como condição primordial da ação pedagógica na interpretação freiriana. 
Em conformidade com Freire, especialmente no que tange ao ordenamento socioeconômico das camadas populares, uma das atribuições da "autonomia é libertar o ser humano das cadeias do determinismo neoliberal, reconhecendo que a história é um tempo de possibilidade" (MACHADO, 2017, p. 53) perante o novo. E, além do mais, “"ensinar a pensar certo' com quem fala com a força do testemunho" (MACHADO, 2017, p. 53) acarreta o apreço pela esperança de poder mudar a realidade. Nessa compreensão, qualquer "processo de autonomia e de construção de consciência nos sujeitos exige uma reflexão crítica e prática, de modo que o próprio discurso teórico terá de ser alinhado a sua aplicação" (MACHADO, 2017, p. 53) na realidade concreta e socialmente constituída de maneira comunicante e solidária.

Freire foi categórico ao considerar que "a incompetência profissional desqualifica a autoridade do professor" (FREIRE, 1996, p. 92) e o seu senso de autonomia. Concomitante a este sentido, lembrou que o professor deve "saber que sem a curiosidade" (FREIRE, 1996, p. 85) motora e inventiva, que provoca a aprendizagem ativa, não é possível aprender nem ensinar com autonomia. $\mathrm{O}$ aprendizado de quem ensina ocorre à proporção que, "humilde, aberto, se ache permanentemente disponível a repensar o pensado [e a] rever-se em suas posições" (FREIRE, 1997, p. 23) autoritárias.

Ao educador cabe compreender "que não existe ensinar sem aprender" [itálicos do autor] (FREIRE, 1997, p. 19) e, por conseguinte, não pode ignorar "que o ato de ensinar exige a existência de quem ensina e de quem aprende" (FREIRE, 1997, p. 19) mutuamente, isto é, em permanente estado de criação e de recriação das condições de diálogo entre educador e educando. E isso, em conformidade com a concepção pedagógica freiriana, é educar com e para a pedagogia da autonomia.

Via de regra, cultiva-se mais a pedagogia da dependência do que a pedagogia da autonomia. Por muito tempo, educadores e educandos têm sido habituados a não discutir, a não debater e a não questionar. Essa negligência para com a aprendizagem crítica e a 
autonomia da díade ensinar-aprender ainda sustenta, habitualmente, a acomodação que oportuniza os mais perniciosos tipos de assistencialismos, inclusive o assistencialismo pedagógico que Freire tanto combateu.

Até então, a pedagogia autoritária inibiu a autonomia de aprender e de inventar no âmbito das salas de aula. Prefere-se não ensinar ao educando cultivar seu senso de autonomia, como se isso parecesse perigoso para quem, enquanto educador, ainda não se libertou daquilo que, de modo concreto, ele mesmo precisa se dar conta da necessidade de ser agente de sua autolibertação. Logo, só pode inventar quem se sente livre das correntes que aprisionam a autonomia e a curiosidade. No entanto, este modo de pensar "demanda profundidade e não superficialidade na compreensão e na interpretação dos fatos" (FREIRE, 1996, p. 32) com os quais educadores e educandos se deparam no cotidiano da vida escolar. Ao considerar homem e mundo como um corpus indissociável, faz-se necessário, por outro lado, superar a impostura dos conhecimentos pré-moldados e pré-determinados pelo autoritarismo pedagógico.

A pedagogia freiriana é, pontualmente, oportuna à permanente reconstrução da noção de homem e de mundo através da autonomia, da curiosidade, da inquietação filosófico-científica e da invenção de outras maneiras de ensinar e de aprender. É a partir daí que se pode admitir que somente "existe saber na invenção, na reinvenção, na busca inquieta e impaciente dos homens frente ao mundo, com o mundo e com os outros" (FREIRE, 2019, p. 81) sem, contudo, perder a "consciência do mundo [ou a] consciência de si como ser inacabado" (FREIRE, 1996, p. 57), conectado à realidade e vocacionado a ser mais. Afinal de contas, "somos porque estamos sendo" e, isso, "é a condição, entre nós, para ser" (FREIRE, 1996, p. 33) mais.

Em sequência, entende-se nada valer "o discurso competente se a ação pedagógica é impermeável a mudanças” (OLIVEIRA, 1996, p. 10) ou a autocrítica, a exemplo de quando se impossibilita que a autonomia possa ser livremente exercida por quem se sente 
instigado a ensinar e a aprender. O contrário disso é a conduta que repercute a esterilização da invenção e da "rigorosidade metódica que caracteriza a curiosidade epistemológica" (OLIVEIRA, 1996, p. 38) aventada por Freire. Isto posto, reforça-se o entendimento de que "não há pensar certo" (OLIVEIRA, 1996, p. 49) se concebido de forma solipsista, sem diálogo e sem comunhão.

É imprescindível concordar com Freire que, "na verdade, quem pensa certo, mesmo que, às vezes, pense errado, é quem pode ensinar a pensar certo" (FREIRE, 1996, p. 27) e dar sentido ao conhecimento enquanto processo. De tal modo, esse entendimento somente se materializa a partir de uma ação comunicante e solidária com o outro. Por isso, é que, tampouco, se deve compactuar com o educador ou com o cientista "senhor da verdade" (FREIRE, 1996, p. 63) absoluta, que não dialoga. Isso, a sério, se confirma quando um ou outro "não suspeita sequer da historicidade do próprio saber" (FREIRE, 1996, p. 63) e ignora que a "autonomia é um processo de decisão e de humanização que vamos construindo historicamente, a partir de várias [e] inúmeras decisões que vamos tomando ao longo de nossa existência” (MACHADO, 2017, p. 53) constituída nas entranhas do mundo, cujos efeitos são existencialmente marcantes.

A partir da intencionalidade da pedagogia da autonomia se pode antever que "a curiosidade é já conhecimento" (FREIRE, 1996, p. 55). Isso se caracteriza como oposição radical à transferência do conhecimento meramente mecânico, costumeiramente, disseminada no âmbito das pedagogias imperativas. Na esteira dessa compreensão, o pensar freiriano sugere "criar as possibilidades para a sua própria produção ou a sua construção" [itálicos do autor] (FREIRE, 1996, p. 47) a partir da relação dialética, democrática e existencial do homem com a leitura do mundo.

Por esse motivo, compreende-se que ensinar a ler é envolver-se numa experiência criativa a fim de uma compreensão do homem e do mundo em sentido lato e, concomitantemente, profundo. Dada a pré-leitura da realidade, a "leitura crítica dos textos e do 
mundo tem que ver com a sua mudança em processo" (FREIRE, 1997, p. 26), isto é, com a invenção e a reinvenção do próprio senso de autonomia.

É no respectivo sentido, portanto, que a pedagogia da autonomia deve superar a utilização das intervenções pedagógicas autoritárias e, ao mesmo tempo, subservientes aos sistemas produtores de opressores e de oprimidos. Em tais condições, apenas a educação que se fundamenta na pedagogia da autonomia pode, coerentemente, se opor ao educador cuja disposição inelutável traduz-se na ação de abarrotar "os educandos dos conteúdos de sua narração” (FREIRE, 2019, p. 79) pesada, por vezes, obsoleta e domesticadora. Na verdade, essa é uma operação usualmente esterilizante da curiosidade e do senso de autonomia necessários para a aprendizagem conscientemente focada na liberdade.

De outra perspectiva, há que se compreender que "os homens se educam em comunhão [e] mediatizados pelo mundo" (FREIRE, 2019, p. 96), assim como a partir de "uma pedagogia problematizante e não de uma pedagogia dos depósitos, bancária, que não leva em conta a existência da "História onde há tempo problematizado e não pré-dado” (FREIRE, 1996, p. 72). Isso significa dizer que a história facultada por quem oprime é uma história alienada e alienante, que faz a prática do opressor continuar latente nos desejos do oprimido.

Essa história, portanto, é submissa a uma leitura acrítica das mazelas da política, da fome, do assistencialismo e da ignorância incubada na sociedade autoritária e opressora, ao mesmo tempo em que renuncia à "solidariedade enquanto compromisso histórico de homens e mulheres" (FREIRE, 1996, p. 11) em busca de uma "ética universal do ser humano" (FREIRE, 1996, p. 11), quer dizer, a propósito de um mundo mais justo e melhor para todos. Nesse caso, um e outro devem estar inseridos como sujeitos históricos no mundo, e agir com autonomia e percepção crítica da própria capacidade de autotransformação. 


\section{A pedagogia da autonomia como ideal de Paulo Freire}

Freire assumiu uma postura radicalmente contrária às práticas pedagógicas que estimulam " $\mathrm{O}$ individualismo e a competitividade" (FREIRE, 1996, p. 11) na sociedade e que, muitas vezes, são reproduzidas no sistema educacional. Ademais, essa convicção pedagógica - que perpetua as condições de opressão e de submissão - carece de ser afetada pela percepção crítica conciliada com a práxis humanizadora entre o sujeito que ensina e o sujeito que aprende. Isso deve suceder não somente na aprendizagem dos conteúdos, mas associadamente a tudo que diz respeito à solidariedade entre os seres humanos, especialmente em relação a educadores e educandos compromissados com a ética, a promoção da justiça e a concretização do ser mais.

O pensamento freiriano, especialmente no que concerne à sua concepção de pedagogia da autonomia, respeita o ser humano em suas diferentes possibilidades de ser. Por isso, essa compreensão se opõe à tradição pedagógica autoritária e, de modo consequente, também opressora. Nesse entendimento, Freire se posicionava inexoravelmente contrário a quaisquer ações pedagógicas especializadas em fazer "comunicados e depósitos que os educandos, meras incidências, recebem pacientemente, memorizam e repetem" (FREIRE, 2019, p. 80) em detrimento de sua autonomia reflexiva.

Quando isso, de fato, ocorre no âmbito pedagógico, os educandos acabam se abnegando da própria curiosidade e da intuição inventiva. Ante tal situação, o pensamento freiriano se contrapõe a qualquer forma de ação pedagógica que nega a autonomia do educando e o entendimento de que "o diálogo é uma exigência existencial" (FREIRE, 2019, p. 109) movida por todo e qualquer ato de ensinar e de aprender, de forma crítica e humanizadora.

A concepção pedagógica de Freire, no que lhe diz respeito, corrobora que educadores e educandos não podem, na prática, "escapar à rigorosidade ética” (FREIRE, 1996, p. 15) nem suplantar a esperança num mundo em que - conforme suas palavras reprodu- 
zidas por Ana Maria Araújo em seu artigo Paulo Freire: sua vida, sua obra - muita "coisa se vem conquistando" (FREIRE, 2015, p. 11) e, dessa maneira, pode-se dizer que "o mundo está melhorando" (FREIRE, 2015, p.11) e, portanto, esse é o mundo que carece de ser anunciado.

Ao partir do pressuposto de que a educação pode proporcionar algo melhor, o pensamento freiriano se configura como concepção pedagógica capaz de perceber a boniteza do mundo e do homem sem, contudo, negar a singeleza da linguagem construída de histórias e de metáforas experienciadas no calor das circunstâncias existenciais. Nessa compreensão, a pedagogia da autonomia entende que a "criticidade não pode ou não deve ser feita a distância de uma rigorosa formação ética ao lado sempre da estética" (FREIRE, 1996, p. 32), cuja admissibilidade da "boniteza deve achar-se de mãos dadas com a decência e com a seriedade" (FREIRE, 1996, p. 24) da docência e da aprendizagem voltadas para um autêntico processo de libertação pedagógica.

Em razão disso, "Freire viveu seu tempo com consciência, sensibilidade ética e um amor grandioso pelo ser humano" (TROMBETTA; TROMBETTA, 2017, p. 111) sem menorizar suas utopias, suas esperanças e sua autonomia. Nessa perspectiva, a "vida há que ser bonita, não só a vida do indivíduo, mas a realização de um povo" (RENDIN, 2017, p. 60) plenamente livre, tal como foi o seu entendimento em relação a suas concepções de pedagogia da autonomia e de pedagogia da libertação.

O arcabouço teórico e pedagógico freiriano, de modo geral, corrobora a ousadia e a desobediência à educação autoritária. Tal entendimento aponta que a inflexibilidade do autoritarismo pedagógico, sistematicamente, "nega a educação e o conhecimento como processos de busca" (FREIRE, 2019, p. 81) e de inacabamento do próprio homem, daí Freire ter dito: "Onde há vida, há inacabamento" (FREIRE, 1996, p. 50) e, decerto, expectativa para o devir do ser mais. E, certamente, essa noção de inacabamento engendra a expectativa de um novo homem, quiçá melhor e mais 
ciente de seu processo de humanização. É nessa acepção que, para ele, o ser humano é "um ser no mundo e com os outros envolvidos num processo contínuo de desenvolvimento intelectual, moral, afetivo" (TROMBETTA; TROMBETTA, 2017, p. 221), a fim de, sempre, ser mais.

Esse respectivo ideal, ora arraigado no amor ao homem e ao mundo, é uma alternativa de mudar a realidade a partir de uma transformação radical das circunstâncias existenciais de cada indivíduo, sem deixar que a pedagogia da autonomia renuncie a ser alegre, inventiva e curiosa. De acordo com essa acepção, é "a curiosidade que nos move e que nos põe pacientemente impacientes diante do mundo que não fizemos, acrescentando a ele algo que fizemos" (FREIRE, 1996, p. 32) como seres humanos, ou que amamos, tal como nosso espírito livre e inventivo queira assim proceder. De tal forma, a "curiosidade é concebida por Paulo Freire como necessidade ontológica que caracteriza o processo de criação e recriação da existência humana" (FREITAS, 2017, p. 107) num mundo humanamente possível.

É importante salientar que a formação ética preconizada por Freire se confirma num mundo que está sendo, onde nenhuma ação humana foi definitivamente terminada. Assim como ninguém pode estar com os outros de forma neutra ou descompromissada com a própria existência, a formação do educador está sempre em situação de transição, e isso "não se faz sem abertura ao risco e à aventura do espírito" (FREIRE, 1996, p. 69) livre, que destemidamente perpassa as veredas do conhecimento.

Nessa compreensão, a "experiência docente, se bem percebida e bem vivida, vai deixando claro que ela requer uma formação permanente do ensinante (FREIRE, 1997, p. 19), ao mesmo tempo em que se deve fundar, reiteradamente, "na análise crítica de suas práticas” (FREIRE, 1997, 19) cotidianas. É nessa acepção que a criticidade, para Freire, pode ser entendida como a "capacidade do educando e do educador refletirem criticamente a realidade na qual estão inseridos, possibilitando a constatação, o conhecimento e a intervenção 
para transformá-la" (MOREIRA, 2017, p. 97) de forma substancial. Portanto, é nessa vertente que a pedagogia da autonomia se define como emersão da noção de criticidade ante a educação bancária, assujeitada aos determinismos do totalitarismo pedagógico.

Ao educador, segundo compreensão destas indicações, deve ser dado o discernimento de que não se pode ensinar o que não se sabe (FREIRE, 2019) ou, apenas, se imagina saber. A consciência da própria ignorância torna-se fundamental para que o educador mude, de forma significativa e processual, a sua prática docente. Por esse motivo, aquilo que se sabe tem que ser testemunho (FREIRE, 2019, p. 98) de toda convicção filosófica, científica, pedagógica e ética. Desse modo, toda prática docente mostra-se caracteristicamente humana e, por isso, precisa ser compromissada com a vida em suas possíveis eventualidades políticas, pedagógicas, existenciais, etc.

Pode-se dizer que educar é, portanto, uma ação que não pode abrir mão da autonomia, mas, sim, precisa abraçá-la como condição indispensável da autêntica experiência pedagógica. Nas palavras de Freire, quer dizer que no momento em que "vivemos a autenticidade exigida pela prática de ensinar-aprender participamos de uma experiência total, diretiva, política, ideológica, gnosiológica, pedagógica, estética e ética" (FREIRE, 1996, p. 24), de tal forma que, considerando a plena autonomia de ensinar e de aprender, "a boniteza deve achar-se de mãos dadas com a decência e com a seriedade" (FREIRE, 1996, p. 24) necessária a qualquer prática pedagógica libertadora.

\section{Considerações finais}

Este artigo não almeja ser uma posição fechada a outras argumentações, críticas e entendimentos adversos. Por isso, a ideia de transformação e de inconclusão é parte integrante da concepção freiriana de sujeito e de mundo, mas, do mesmo modo, constitui a tessitura cervical deste texto.

Entende-se que a pedagogia da autonomia consiste, fundamentalmente, em transcender os ditames do ideário pedagógico 
pré-dado e pretensamente absoluto, alçado em concepções e práticas pretensamente definitivas. Assim, essa concepção pedagógica não pode se negar a transformar o mundo através do diálogo, ao mesmo tempo em que precisa somar força e resistência a quaisquer autoritarismos pedagógicos vigentes. Agindo nessa perspectiva, o educador torna-se capaz de perceber seu fazer histórico como possibilidade de, permanentemente, interagir com o processo de transformação da realidade e de si mesmo, o que, em regra, se mostra coerente com a percepção autolibertadora difundida pela pedagogia da autonomia.

Essa concepção pedagógica fundamenta o modo de ser humano entendido como processo de mudança e de autotransformação. Nesse ponto de vista, a relação dialógica entre educador e educando abre-se irrestritamente para a experiência cotidiana manifestada na autonomia de aprender e de ensinar. Por isso, vivenciar a autonomia pedagógica é, em grande parte, constituir uma experiência plena de autolibertação.

Em sentido freiriano, a respectiva pedagogia da autonomia se mostra como construção da percepção crítica manifestada na relação entre a teoria e a prática, entre o discurso e a ação entendidos como continuação da construção e reconstrução de novos significados para a educação. Portanto, a autonomia pedagógica consiste no exercício contínuo de se libertar das convenções e das limitações inerentes ao contexto histórico das pedagogias autoritárias.

Logo, a tal propósito, faz-se necessária e impassível a conduta reflexiva permanente sobre a experiência da liberdade em seu viés pedagógico. Pois, não pode haver emancipação pedagógica sem autonomia do pensar e do agir críticos, um e outro estão comprometidos com a liberdade. Sendo dessa forma, a autonomia pedagógica só se concretiza, de fato, na comunhão entre os homens livres que ensinam e que aprendem - e que são livres porque romperam com a noção ingênua da liberdade pré-dada ou assistencialmente concedida.

Em sequência, compreende-se que a autonomia pedagógica também é conquista mútua de educadores e de educandos. E somen- 
te ela é devidamente apropriada para libertar ambos do jugo da educação dura e autoritária. Concomitante a isso, é com autonomia que se pode ressignificar a prática pedagógica intransigente em uma prática pedagógica libertadora, tal como foi a intencionalidade de Freire.

Em suma, é necessário ser livre para apreender a experiência única de humanizar o homem pela solidariedade local e universal, real e utópica, a fim de que, sendo livre, também se possa ser mais.

\section{Referências}

FREIRE, Ana Maria Araújo. Paulo Freire: sua vida, sua obra. In: EDUCAÇÃO EM REVISTA. Marília, SP, v. 2, n. 1, 2001a. Disponível em: <http://www2.marilia.unesp.br/revistas/index.php/educaçãoemrevista/article/view/663/546>. Acesso em: 11 de ago. de 2015.

FREIRE, Paulo. Pedagogia do oprimido. 69. ed. Rio de Janeiro: Paz e Terra, 2019.

FREIRE, Paulo. Professora sim, tia não: cartas a quem ousa ensinar. São Paulo: Olho d'Àgua, 1997.

FREIRE, Paulo. Pedagogia da autonomia: saberes necessários à prática educativa. 27. ed. Paz e Terra, 1996.

FREITAS, L. S. de. CURIOSIDADE EPISTEMOLÓGICA. In: STRECK Danilo R.; REDIN, Euclides; ZITKOSKI, Jaime J. (Orgs.). Dicionário Paulo Freire. 3. ed. Belo Horizonte: Autêntica, 2017.

MACHADO, R. de C de F. AUTONOMIA. In: STRECK Danilo R.; REDIN, Euclides; ZITKOSKI, Jaime J. (Orgs.). Dicionário Paulo Freire. 3. ed. Belo Horizonte: Autêntica, 2017.

MOREIRA, Carlos Eduardo. In: STRECK Danilo R.; REDIN, Euclides; ZITKOSKI, Jaime J. (Orgs.). Dicionário Paulo Freire. 3. ed. Belo Horizonte: Autêntica, 2017.

OLIVEIRA, E. C. de. PREFÁCIO. In: FREIRE, P. Pedagogia da autonomia: saberes necessários à prática educativa. 27. ed. Paz e Terra, 1996.

REDIN, E. BONITEZA. In: STRECK Danilo R.; REDIN, Euclides; ZITKOSKI, Jaime J. (Orgs.). Dicionário Paulo Freire. 3. ed. Belo Horizonte: Autêntica, 2017.

TROMBETTTA, S.; TROMBETTA, L. C. Docência. In: STRECK Danilo R.; REDIN, Euclides; ZITKOSKI, Jaime J. (Orgs.). Dicionário Paulo Freire. 3. ed. Belo Horizonte: Autêntica, 2017. 